\title{
ESTUDO DE MANIFESTAÇÕES PATOLÓGICAS EM FUNDAÇÕES DE EDIFÍCIO DE BANCO PÚBLICO LOCALIZADO EM BRASÍLIA - DF
}

\author{
CAVALCANTE, AMANDA DOS SANTOS \\ Estudante \\ Universidade Católica de Brasília - UCB \\ Distrito Federal; Brasil \\ mandasc@outlook.com
}

\author{
VIEIRA, LORENA MARIA \\ Estudante \\ Universidade Católica de Brasília- UCB \\ Distrito Federal; Brasil \\ lorena.maria.vieira@gmail.com
}

\author{
JESUS, SYLVIA REGINA CORRÊA BRANT PEREIRA DE \\ Professora, Doutora \\ Universidade Católica de Brasília - UCB \\ Distrito Federal; Brasil \\ sylvia.pereira@p.ucb.com
}

\begin{abstract}
Resumo:
O presente trabalho traz um estudo de caso a respeito de um reforço estrutural feito em um bloco de coroamento. O objetivo da pesquisa foi realizar uma análise comparativa, levantando as principais causas de manifestações patológicas em fundações, as possíveis soluções e, concomitantemente, investigando de forma crítica se as soluções propostas no relatório técnico são apropriadas para o caso. Foi observado que o bloco de coroamento, inicialmente, apresentava trincas e fissuras decorrentes de um deslocamento na junta de dilatação, localizada em uma parede curva na estrutura em questão. Foi feita a análise do relatório técnico realizado pela empresa de engenharia contratada pela instituição em questão, além de uma revisão de literatura sobre o tema patologia de fundações. Dessa forma, tendo em vista que as manifestações patológicas em fundações estão relacionadas, principalmente, com a investigação do subsolo, análise e projeto, execução e eventos pós-conclusão, foi verificado que, dois pilares estavam desviados do centro geométrico submetendo, assim, a fundação a um estado iminente de deformação, que veio a ocorrer após uma demolição nas proximidades e a existência de um provável vazamento de águas pluviais e esgoto na área de influência das fundações do local da patologia . Nesse sentido, faz-se necessário o reforço do bloco de coroamento das fundações, o retorno da parede curva para sua posição original, a recuperação do pilar parede e o desvio da caixa de inspeção e esgoto.
\end{abstract}

Palavras-chave: patologia, fundação, reforço.

\section{Abstract:}

This paper presents a case study of a structural reinforcement made in a pile cap. The objective of the research was to perform a comparative analysis, surveying the main causes of foundation failures, the possible solutions and, concomitantly, investigating whether the solutions proposed in the technical report are appropriate for the case. It was observed that the pile cap initially presented cracks and fissures resulting from a displacement in the expansion joint, located on a curved wall in the studied structure. Both the technical report made by an independent engineering firm, and literature on foundation failure were revised and analyzed. Thus, considering that the foundation failures are mainly related to the flaws in any given step of underground investigation, design and review of the project, execution itself or post-completion events, it was found that two columns were deviated from the geometric center. Consequently, the foundation was submitted to an imminent state of straining, which occurred after a nearby demolition event and the likely existence of drainage and sewage pipes leak around the structure. In order to address the issue, it was proposed the reinforcement of the pile cap, the restoration of the curved wall back to its original position, the recovery of the wall column, and the reallocation of the inspection chamber.

Keywords: foundation failures, building structure, structural reinforcement.

\section{INTRODUÇÃO}

Define-se patologia de construções como fundamentos e circunstâncias nas quais as edificações obtêm desempenho abaixo das condições pré-estabelecidas a que está submetida. Considera-se que as manifestações patológicas podem ser causadas por fatores endógenos, como falhas no projeto ou na execução da obra e deterioração natural pelo envelhecimento, ou por fatores exógenos, que ocorrem por ações de terceiros de forma voluntária ou involuntária e por fatores da natureza que não foram previstos no projeto. (VITÓRIO, 2003) 
Sabendo que a composição de uma edificação, de maneira abrangente, é constituída por infraestrutura, superestrutura, alvenaria, revestimentos e sistemas prediais, estas estruturas são passíveis de manifestações patológicas, as quais prejudicam o desempenho da edificação em sua atividade fim, evidenciando, então, a importância do seu estudo.

Seguindo a premissa citada, as fundações das edificações, estruturas usadas na transferência de carga da edificação para o solo, também estão sujeitas a apresentarem manifestações patológicas que podem ter origens em diversos fatores. Na maioria dos casos, o diagnóstico e a solução são considerados difíceis de serem elaborados, uma vez que, sendo o solo um material complexo, suas propriedades podem ocasionar uma variação muito ampla de suas características (MILITITSKY; CONSOLI; SCHNAID, 2005).

De modo geral, verifica-se que as manifestações patológicas em fundações podem ser provocadas por recalque, ausência/ insuficiência de investigação do subsolo, falhas no projeto, execução e possíveis eventos após sua finalização (VITÓRIO, 2003). Estas manifestações, quando não prevenidas, precisam ser emergencialmente corrigidas, pois se tratam de parte de suma importância da edificação.

Observando a importância do estudo das manifestações patológicas nas fundações, é pertinente ressaltar que, segundo Milititsky; Consoli; Schnaid, (2005), as fundações correspondem de 3\% a 6\% do custo global da obra e, em casos especiais, chegando até $15 \%$ do valor. Desse modo, verifica-se que é exigido atenção a este tipo de estrutura, sendo necessárias manutenções, tanto preventivas quanto preditivas e corretivas para que não seja comprometida por patologias. Cabe destacar que a sua correção pode ser de investimento financeiro bastante significativo, havendo situações em que a empresa pode não conseguir arcar com o valor.

Nesse contexto, vale evidenciar o conceito, segundo a ABNT NBR 5462/1994, dos três tipos de manutenções existentes. Primeiramente, tem-se a manutenção corretiva, que se faz necessária após a ocorrência de um dano na estrutura que ainda é passível de pequenas correções. Já a manutenção que é efetuada em intervalos predeterminados a fim de diminuir as chances de ocorrência de manifestações patológicas é classificada como preventiva. E, por último, define-se a manutenção preditiva, que consiste na aplicação sistemática de técnicas de análise, por meio de supervisões centralizadas ou de amostragem, para reduzir ao mínimo a manutenção preventiva e corretiva.

As manutenções, portanto, são de extrema importância para garantir que as estruturas mantenham suas respectivas atividades conforme previstas em projeto na condição de durabilidade e vida útil. Segundo a ISO 13823/2008, durabilidade é definida como a capacidade de uma estrutura satisfazer os requisitos de desempenho do projeto, com a presença de manutenções em um período de tempo determinado sob a influência ambiental ou de envelhecimento natural da estrutura. Na sequência, entende-se vida útil de projeto (VUP) como o tempo referente ao qual uma edificação/estrutura atendam o desempenho do projeto com as devidas manutenções previstas, realizadas. Os conceitos de vida útil e durabilidade, assim, correlacionam-se diretamente, de forma que a durabilidade das estruturas é essencial para a sua vida útil, sendo associada às características dos materiais e ao meio em que estão instaladas.

Considerando as questões relativas à patologia de construções em fundações, apresenta-se no presente trabalho um caso de manifestações patológicas em fundações. Foram observadas variações na estrutura em um Edifício de Banco Público, localizado em Brasília - DF. A edificação em questão é uma estrutura em concreto armado com 04 (quatro) pavimentos, composta por 03 (três) módulos separados por duas juntas de dilatação. Devido às fundações não serem de fácil acesso para inspeções periódicas, as deficiências apresentadas só foram descobertas mediante as evidências observadas na obra como um todo. Um exemplo disso é a movimentação de uma junta de dilatação, conforme mostrado na Figura 1. 

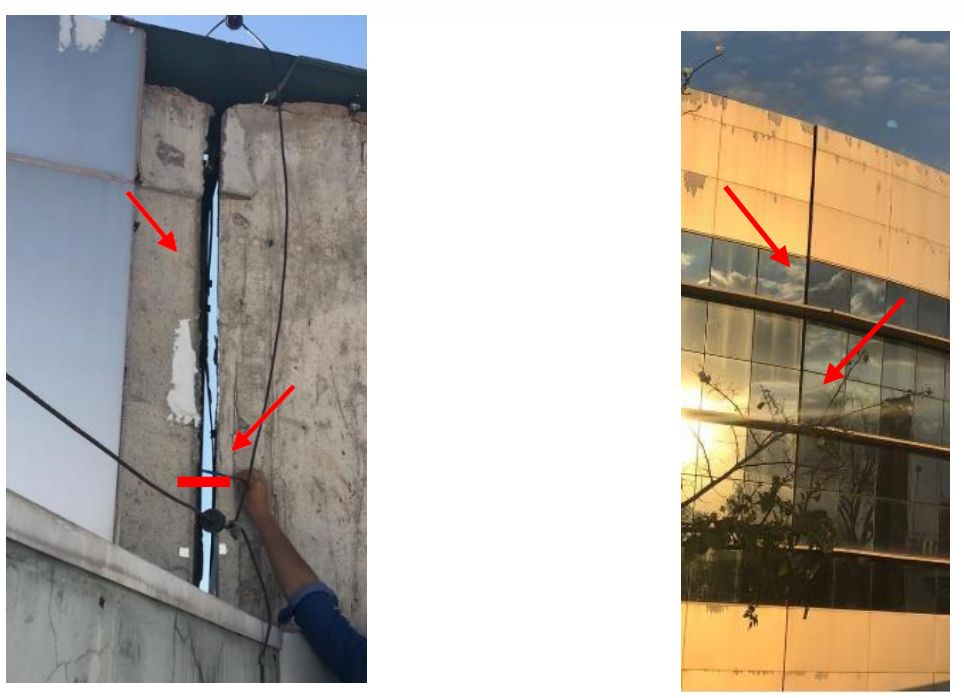

Figura 1 - Junta de dilatação vista pelo lado interno e externo.

Considerando o exposto a respeito da problemática relativa a patologias de construções e, mais especificamente, casos observados em fundações, tem-se por objetivo geral desta pesquisa realizar um estudo de caso sobre o recalque constatado na fundação do Edifício.

Além disso, definem-se como objetivos específicos:

- Identificar os principais problemas identificados como manifestações patológicas de fundações;

- Identificar as principais causas dessas manifestações patológicas;

- Sugerir soluções para correção dessas manifestações patológicas;

- Sugerir solução para o caso de estudo da pesquisa.

\section{MATERIAIS E MÉTODOS}

A estrutura em estudo faz parte do complexo Central de Tecnologia de um Banco público localizado em Brasília DF (Figura 2), com área estimada de $56.000 \mathrm{~m}^{2}$. Este complexo é composto por dois Edifícios: um voltado a áreas administrativas, e o outro, a parte de tecnologia, sendo denominados como edifícios 1 e 2 , respectivamente, na presente pesquisa.

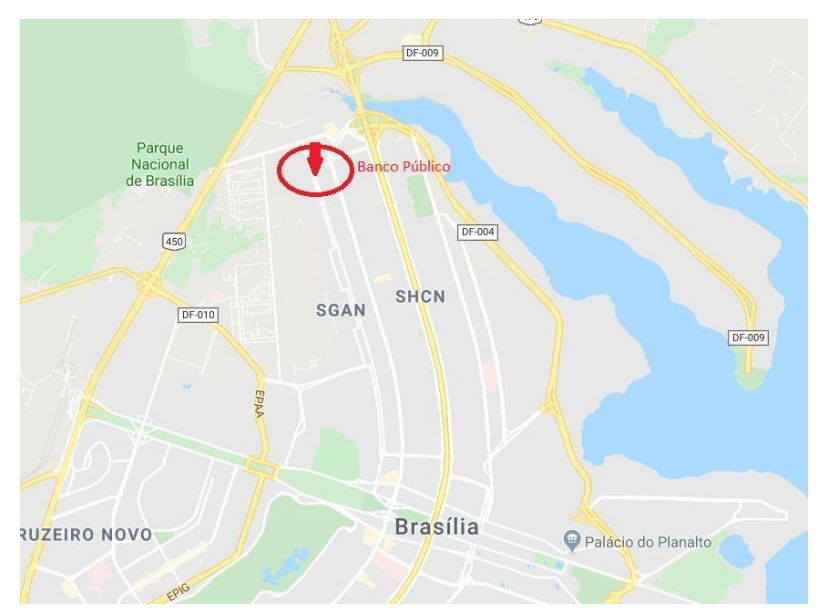

Figura 2 - Localização via Satélite do local em estudo.

O Edifício 2, objeto de estudo em questão, teve sua construção finalizada em 2010, e nele funciona o maior datacenter da instituição financeira, sendo um dos maiores da América Latina, no qual ocorre todo o processamento do Sistema Financeiro Nacional, incluindo o Sistema de Pagamentos Brasileiro e a Compensação Bancária, além de atender às transações online realizadas em 4 (quatro) continentes sendo eles: América, África, Europa e Ásia. 
A manifestação patológica ocorreu em uma parede curva (fachada) do edifício que ocupa uma área de 918,53 $\mathrm{m}^{2}$, aproximadamente 7 anos após a sua construção. A estrutura foi projetada em concreto armado com 04 (quatro) pavimentos, composta por 03 (três) módulos, A, B e C, separados por duas juntas de dilatação (Figura 3). O modelo estrutural é convencional, composto por lajes nervuradas, maciças, vigas e pilares, além de painéis em parede de concreto. As fundações foram executadas em tubulões a céu aberto utilizando perfuratriz mecânica e o alargamento da base foi executado de forma manual.

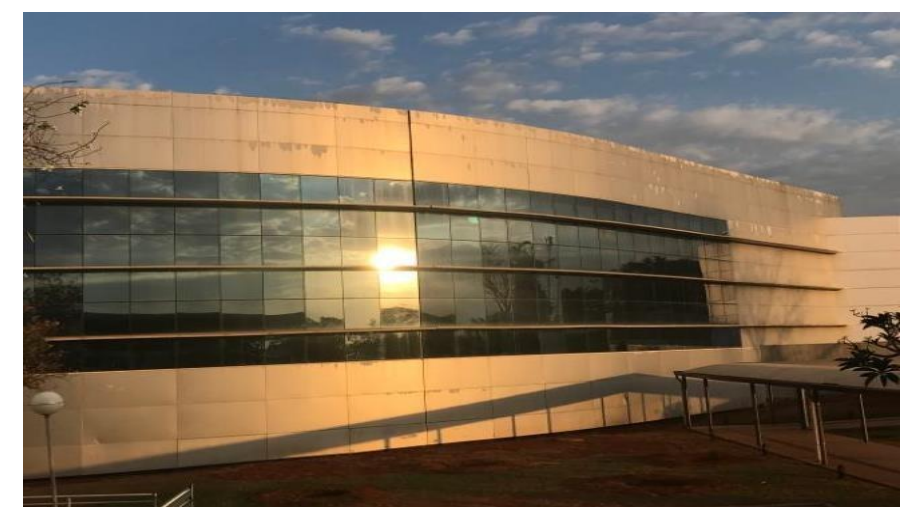

Figura 3 - Fachada do estudo em questão.

Depois de aproximadamente 7 anos e meio, em meados de 2017, foi constatada a movimentação de uma das juntas de dilatação localizadas entre os módulos A e B, que gerou um desalinhamento no eixo vertical entre os módulos e também um afastamento nas faces das fachadas, conforme se vê em detalhe na Figura 4.

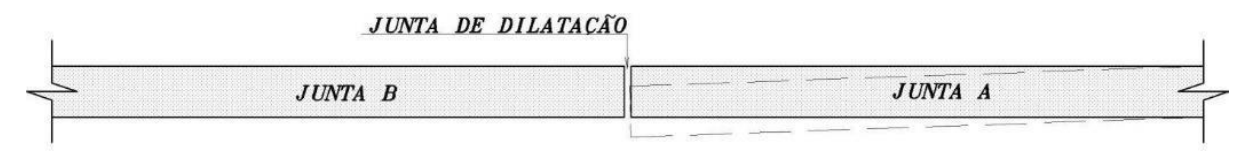

Figura 4 - Planta baixa do lado externo.

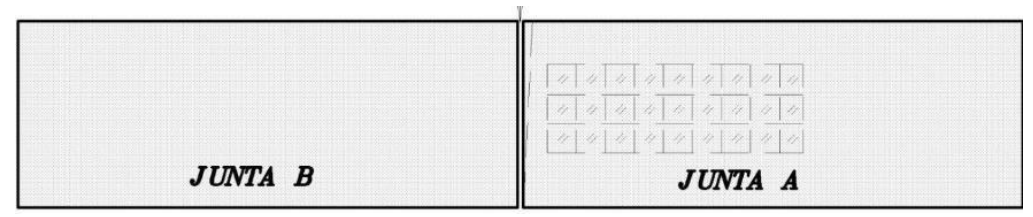

Figura 5 - Vista Frontal lado externo da junta de dilatação.

Ao realizar estudos e inspeções a respeito da movimentação, constatou-se também a presença de trincas e fissuras no bloco de coroamento, conforme mostrado nas Figuras 6 e 7.

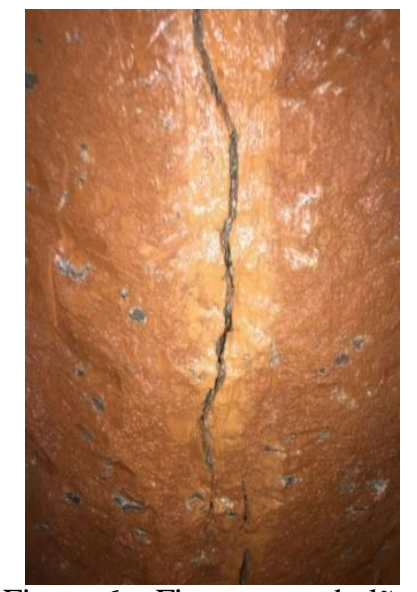

Figura 6 - Fissura no tubulão.

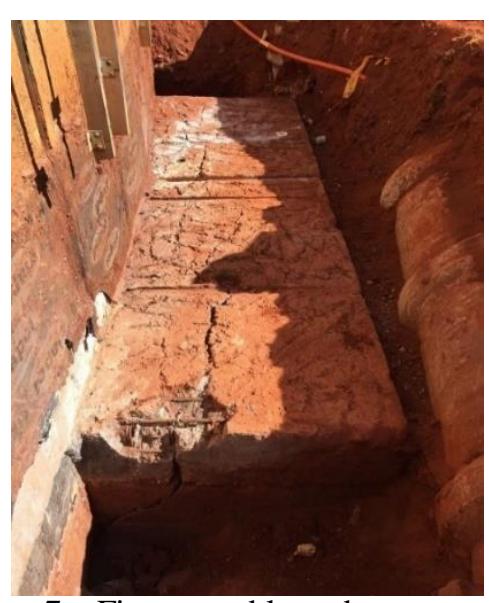

Figura 7 - Fissura no bloco de coroamento.

A partir de ensaio Standard Penetration Test (SPT) e recolhimento de amostras realizado em julho de 2018, foi possível caracterizar o solo do local de estudo. Nos 14 metros iniciais, tem-se argila pouco siltosa com areia fina e consistência/compacidade de muito mole a média e cor avermelhada. Após os 14 metros, até o limite da sondagem no 
ponto 19,4 metros, encontrou-se argila siltosa com areia fina, consistência/compacidade de rija a dura e cor avermelhada.

Tendo em vista, portanto, as manifestações patológicas apresentadas na estrutura em estudo neste trabalho, optou-se por, primeiramente, realizar revisão de literatura em livros técnicos, artigos científicos, dissertações e teses sobre o grande tema de estudo na presente pesquisa: manifestações patológicas em fundações. Ademais, foram coletadas informações sobre o caso de estudo com base no laudo técnico elaborado pela empresa responsável pela inspeção e pela determinação das causas e da solução da patologia do empreendimento em questão, assim como suas plantas e projetos estruturais.

A finalidade da revisão sugerida é a análise e a definição das possíveis causas da ocorrência de um suposto recalque na fundação, gerando, assim, as fissuras e movimentações mostradas. Dessa forma, tendo o conhecimento das causas, pretende-se indicar possíveis soluções para o problema, bem como analisar de forma técnica a solução implementada pela empresa de engenharia contratada pela instituição bancária.

\section{RESULTADOS}

As fundações são elementos estruturais que fazem ligação entre a edificação e o solo. São posicionadas no solo e, por este motivo, é possível que sofram deslocamentos. Com base neste pressuposto, segundo Milititsky; Consoli; Schnaid, (2005), infere-se que variados tipos de recalques podem causar problemas nas estruturas, como as fissuras, que são resultados da superação da resistência dos componentes pela tensão gerada pelo movimento, ou até mesmo recalques que são admitidos no projeto, já prevendo essa possível movimentação que pode ocorrer na interação solo-fundação.

Os recalques admissíveis, se definidos com precisão no projeto, não causam danos à estrutura, haja vista estarem dentro de um limite preestabelecido de segurança e terem seu desempenho garantido durante a vida útil da obra. Deve-se destacar, porém, que este tipo de recalque não é facilmente determinado em decorrência do comportamento do solo e das estruturas, e, portanto, ainda não se tem nem no plano teórico, nem em práticas empíricas uma solução precisa para diferentes cenários. (MILITITSKY; CONSOLI; SCHNAID, 2005)

Portanto, sabendo-se da possibilidade da movimentação do solo e que esta pode causar recalques tanto dentro de um limite esperado quanto prejudiciais, pode-se atribuir a estes motivos o surgimento de manifestações patológicas em fundações. Segundo Milititsky; Consoli; Schnaid, (2005), as principais causas estão relacionadas à investigação do subsolo, análise eprojeto, execução e eventos pós-conclusão (Figura 8) que serão discutidas no presente trabalho.

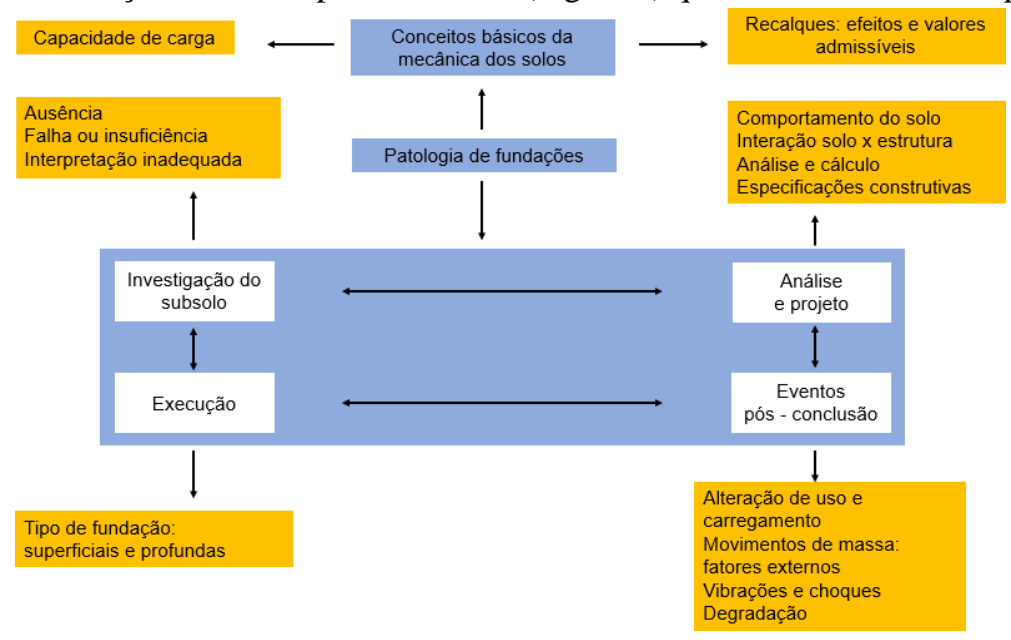

Figura 8 - Fluxograma de possíveis causas patológicas.

\subsection{Principais Causas de Manifestações Patológicas em Fundações}

De acordo com o que foi discutido, serão apresentadas a seguir as principais causas de manifestações patológicas elencadas no fluxograma da Figura 8.

\subsubsection{Investigação do Subsolo}

Uma das causas mais recorrentes de manifestação patológica em fundações, segundo Milititsky; Consoli; Schnaid, (2005), é a ausência/falha na investigação de forma correta e precisa do subsolo. A investigação do subsolo é de extrema importância, pois o solo servirá para suportar as cargas da edificação. Portanto, projetar uma estrutura de fundação sem o conhecimento de suas características e de seu comportamento pode acarretar diversos problemas no caso de 
ausência de investigação nos diferentes tipos de fundações.

Geralmente a ausência total de investigação do subsolo é comum em obras de pequeno porte, podendo ocasionar graves manifestações patológicas. Dessa forma, é inadmissível a execução dessa prática, tendo que seguir a normalização corrente (ABNT NBR 6122/2010; ABNT NBR 8038/1983). No entanto, mesmo sendo realizada a investigação do subsolo, ela pode ser insuficiente, não caracterizando, muitas vezes, dados importantes, prática que pode prejudicar a estrutura da edificação. Número insuficiente de furos de sondagem; profundidade de investigação insuficiente, não particularizando camadas de solo e, potencialmente, comportamento diferentes; falta de ensaios especiais, caso necessário, o que pode ocasionar na não determinação de propriedades de comportamento; situações com grande variação de propriedades, são alguns exemplos comuns, segundo Milititsky; Consoli; Schnaid (2005).

Outros problemas recorrentes na fase de investigação são falhas que podem ocorrer durante fases distintas do processo, sendo capazes de prejudicar o resultado esperado. Na sondagem, a localização errada ou incompleta do sítio da obra é um exemplo de falha recorrente ou ensaios realizados de forma não padronizada, assim como o uso de equipamento com defeito e a má descrição do tipo de solo também podem afetar os resultados.

Na sequência, uma interpretação inadequada dos dados do programa de investigação pode não considerar os valores representativos e, dessa forma, não identificar os problemas no solo.

Por último tem-se os casos especiais, que são aqueles que não estão no alcance do projeto de investigação, mas que têm influência direta com as fundações, como:

- Influência da vegetação: ação direta das raízes, que pode ser física ou na mudança do teor de umidade do solo, pois estas retiram água do solo para manter seu crescimento.

- Colapsibilidade: solos colapsíveis.

- Expansibilidade: Ocorre principalmente em fundações superficiais; é a variação de volume causada pela presença de argilominerais expansivos em solo argiloso, em detrimento da alteração do teor de umidade.

\subsubsection{Análise e Projeto}

Segundo Milititsky; Consoli; Schnaid, (2005), a partir de investigações geotécnicas e inspeções, define-se o tipo de subsolo, sendo ele um dos componentes de diagnósticos para o problema de fundações. Outros dois fatores importantes são as determinações das solicitações ou cargas de projeto. Contudo, o projeto de fundações é composto por detalhes de indicações do projetista, especificações construtivas e indicações de normas específicas. Por conseguinte, as principais manifestações patológicas durante a vida útil das fundações serão representadas da seguinte maneira:

\subsubsection{Manifestações patológicas abrangendo o comportamento do solo}

Sendo o solo um material natural, sujeito à grande variabilidade e que, pode ser sujeito a comportamento mecânico e hidráulico em diferentes seções dele, os problemas decorrentes do seu comportamento são abundantes e as investigações na etapa de análise e projeto precisam ser executadas de maneira técnica e rigorosa. Com isso, de acordo com Milititsky; Consoli; Schnaid, (2005) segue alguns exemplos desse tipo de problemas: 1. Desconsideração de caracterização completa das camadas existentes do solo, resultando em problema no desempenho das fundações, podendo atender apenas alguns perfis do subsolo, e não todos. 2. Representações ineficazes do comportamento do solo em determinado local causadas por relações empíricas extrapoladas de ensaios NSPT provenientes de outro solo. Entende-se que, para cada tipo de solo, não se pode admitir o mesmo dado de um ensaio qualquer. 3. Imprecisão na estimativa das características do comportamento do solo por ultrapassar ou não o valor adequado à situação. Com isso, exemplos característicos são: A estimativa da resistência ao cisalhamento por meio de NSPT, na qual o valor da penetração pode chegar a zero ou próxima de zero; exceder a penetração dos ensaios SPT em rochas alteradas para obter valores da tensão admissível ou resistência de ponta para os casos de fundações profundas (NSPT > 100). 4. Utilização inadequada de dados de ensaios (SPT ou CPT) de acordo com o tipo de solicitação para fins de estimativa de propriedades do solo. 5. Escolha do tipo de fundação não apropriada para o tipo de comportamento do solo local, e fundações com falhas na execução.

\subsubsection{Manifestações patológicas causadas pela ausência de reconhecimento de mecanismos}

São inúmeros os problemas envolvendo os mecanismos de interação solo-estrutura causadores de colapso e mau comportamento. Podem ser citados, a seguir, como alguns desses exemplos: 1. Transferência de carga das fundações para o solo de maneira sobrepostas ou isoladas. Quando sobrepostas, podem ser iniciadas durante o planejamento da obra ou 
pela introdução de uma edificação vizinha. 2. Conjunto de estacas apoiadas em solos não resistentes, desconsiderando camadas finas e de solos moles abaixo da camada compacta, e/ou na ponta das estacas. 3. Fundação superficial próxima à escavação não compactada, sujeita a esforços horizontais. 4. Execução de estacas próximas a pilares, sem considerar o efeito de sobrecargas e futuro danos construtivos possíveis. 5. Falta de consideração do fato para eventuais efeitos de atrito negativo em estacas. Ocorre com o deslocamento do solo: podendo estes serem típicos de solos moles e colapsíveis, deformam mais que o elemento de fundação. 6. Atritos negativos ou solos em adensamento, ao longo de estacas inclinadas, ocasionando solicitações de flexão para as quais a fundação não foi dimensionada. 7. Aterro irregular sobre solos moles, ocasionando o surgimento de solicitações horizontais nos elementos de fundação profunda, comprometendo- os quando não considerado o aterro no cálculo. 8. Utilização do método do cone de arrancamento em fundações profundas tracionadas, ocasionando resultados com valores acima do normal e estado duvidoso. 9. Com base na soma das cargas de ruptura de estacas individuais, obtém-se o valor do cálculo para tração de grupo de estacas, resultando em valores inferior ao somatório das estacas individuais por conterem a cinemática de grupo diferentes. 10. Aplicação de cargas de trabalho nominais sem constatação de flambagem de estacas em solos moles.

\subsubsection{Manifestações patológicas causadas pela ausência de reconhecimento do comportamento real das fundações}

As fundações se comportam diferentemente uma das outras, desta forma, apresentam deformações distintas, prejudicando assim o desempenho das estruturas alicerçadas sobre elas. Portanto, segundo Milititsky; Consoli; Schnaid, (2005), seguem alguns exemplos dessas patologias: 1. Sistemas de fundações diferentes ocasionados por cargas diferentes, em subsolos com desconformidade na profundidade de camadas resistentes, não separados por junta, propiciando recalques diferenciais. 2. Obtenção de valores de capacidade de carga mediante ensaio de penetração, para fundações profundas não analisando o número limite de atrito lateral, e de resistência de ponta. Com isso, os resultados não são compatíveis, fazendo assim a provocação do mau comportamento das fundações. 3. Fundações profundas com presença de aterros compactados sob camadas de solos compressíveis, gerando assim, grandes recalques. 4. Falta de reconhecimento da movimentação da resistência de ponta em estacas com diâmetros elevados, na qual a resistência de ponta carece de deslocamentos relativos ao diâmetro das estacas. Com isso, resultam na adoção de valores não adequados à situação e proporcionam recalques incompatíveis com o funcionamento da superestrutura. 5. Situações de carregamentos diferentes para uma mesma estrutura, sem junta de comportamento, ocasionando trincas e recalques diferenciais. 6. Reforço em fundações profundas com problemas executivos, sem considerar o efeito, deslocamentos ou rigidez do novo elemento executado. 7. Utilização de fundações de desempenhos diferentes para uma mesma estrutura, sem considerar o impacto de carregamentos especiais.

\subsubsection{Manifestações patológicas abrangendo a estrutura da fundação}

Segundo Milititsky; Consoli; Schnaid, (2005), inúmeras são as falhas envolvendo a estrutura da fundação decorrentes dos danos causados pelo detalhamento dos elementos de fundação ou projetos: 1. Definição incorreta das cargas operantes nas fundações, característico de projetistas sem experiência ou obras sem projeto adequados. 2. Projeto de fundação considerando apenas a carga final operante. Casos comuns em estruturas com etapas construtivas e estruturas pré-moldadas. 3. Dimensionamentos inadequados de elementos estruturais de fundações, especificamente utilização de cálculos de vigas contínuas para uso de vigas de rigidez elevada, vigas de equilíbrio, blocos com erro no dimensionamento ocasionando falhas na distribuição de solicitações. 4. Cálculo da armadura de estacas de concreto armado sem considerar a hipótese de fissuração do concreto. Resultando assim, em aberturas de fissuras, e ocasionando possíveis corrosões na armadura. 5. Utilização de estacas metálicas com emendas, sem análise de possíveis carregamentos de tração, gerando instabilidade na mesma. 6. Utilização de projeto estrutural que não considera a estabilidade global. 7. Escassez de detalhamentos estruturais, como no cobrimento de concreto das armaduras ou a ligação da armadura ao bloco, ocasionando assim, erros na execução. 8. Utilização de armaduras densas no projeto, resultando em impasses na execução. 9. Utilização de solicitações do nível do solo/terreno, para fundações.

\subsubsection{Manifestações patológicas abrangendo as especificações construtivas}

Os procedimentos construtivos devem satisfazer as especificações de projeto de elementos estruturais (fundação superficial ou profunda) de acordo com Milititsky; Consoli; Schnaid, (2005). Portanto, em casos da não determinação específica, podem manifestar patologias relativas a:

- Em fundações superficiais: 1. Reconhecimento da cota de assentamento das fundações. 2. Locais de assentamento das fundações, propriedades e tipos de solos. 3. Ausência de recomendação de mandato de execução de elementos adjuntos em níveis de cota diferentes. 4. Propriedades e resistência do concreto. 5. Tensão admissível do solo. 6. Cobrimento das armaduras sem especificação; 
- Em fundações profundas: 1. Profundidade mínima do projeto. 2. Particularidades e peso mínimo do martelo de cravação. 3. Propriedades mínimas do equipamento de execução, ocasionando a insuficiência de execução. 4. Características e tensões mínimas dos materiais de execução das estacas. 5. Detalhes perfeitamente claro em caso de emendas. 6. Controle do comportamento de estacas. 7. Cuidados especiais em locais suscetíveis à desgastes/erosão.

- Em relação aos problemas envolvendo tanto fundação superficial quanto profunda, podem-se citar: 1. Falta de designação do local dos ensaios e sondagens realizadas para embasamento nos projetos, podendo ocasionar mudanças na geometria do terreno, como também os comprimentos máximos e mínimos. 2. Ausência de designação das cargas do projeto, e também a identificação e data das plantas de carga das fundações em caso de recebimento de outro profissional, ocasionando desconformidade na solução proposta se houver situações de alteração de projeto.

\subsubsection{Manifestações Patológicas Durante a Execução}

O êxito ao final de uma execução de fundação não depende apenas de cálculos, projetos e uma boa caracterização do subsolo, como também do processo construtivo adequado, sendo executado por profissionais habilitados, experientes, e apropriação de equipamentos; caracterização e detalhamento explícitos dos procedimentos e materiais a serem utilizados, tendo todos esses uma excelente assistência de fiscalização e controle construtivo preciso.

Sabendo-se que as investigações geotécnicas podem ser classificadas como o primeiro responsável pelos problemas de comportamento das fundações, as imperfeições de execução consistem no segundo maior problema de comportamento das fundações. Ainda que haja a contratação de empresas especializadas, é indispensável a fiscalização do serviço, fazendo, portanto, anotações de dados relevantes para demais necessidades de amostragem ao projetista em casos especiais, ou as condições executivas existentes. (MILITITSKY; CONSOLI; SCHNAID, 2005).

Levando em conta os possíveis problemas em fundações superficiais, fundações profundas, volume de concreto, ensaios e provas de carga, ressaltam-se alguns deles em casos de fundações profundas a seguir. A elaboração de projeto das fundações profundas está relacionada exatamente às características de execução, e não somente ao perfil do solo e métodos específicos de cálculo. Portanto, elas são distintas dos demais elementos de fundação por elas apresentarem particularidades. Nem sempre as fundações são executadas conforme o planejado, em razão de oscilações das características do subsolo apontadas na investigação, variações das situações de campo/canteiro, e limitações na amplitude de equipamentos. É fundamental o bom detalhamento do processo construtivo para obtenção de um bom desempenho. Contudo, considera-se também que a execução da fundação profunda pode interferir nas construções vizinhas ou até mesmo no solo, ocasionando alterações no projeto inicial. Portanto, é válido examinar a estabilidade própria e vizinha, e analisar o método de cálculo para verificação da efetividade da solução proposta.

Por conseguinte, segundo Milititsky; Consoli; Schnaid, (2005), os problemas apresentados em fundações profundas comuns a mais de um tipo de método construtivo são: 1. Falhas na locação de estacas ou desconsideração de excentricidade. 2. Falhas na execução ou desvios por aparecimento de blocos dissipados na massa de solo. 3. Execução de estacas com diâmetro e tamanho menor que o de projeto, ocasionando baixa resistência. 4. Inclinação final incompatível com o previsto em projeto. 5. Limpeza desapropriada na cabeça das estacas para junção com o bloco. 6. Alteração de materiais ou ferramentas por elementos equivalentes no canteiro. 7. Cota de arrasamento oposto ao projetado.

8. Posicionamento impróprio ou ausência de armadura no topo do elemento de fundação ou fretagem de projeto no bloco. 9. Utilização de concreto com características diferentes do sugerido.

\subsubsection{Eventos pós Conclusão}

Após o término de um empreendimento com o seu plano de projeto e execução compatíveis com o esperado, ainda podem ocorrer eventos que causam patologias nas estruturas das fundações e na superestrutura da edificação. Podese dizer que é comum ocorrer a alteração do uso da estrutura para qual ela foi projetada ou ampliações não previstas e, com isso, modificar-se significativamente o carregamento próprio da estrutura.

Dessa maneira, torna-se possível, então, problemas de comportamento resultantes das mudanças nas solicitações. As novas situações de distribuição ou concentração de cargas podem provocar recalque ou exceder a capacidade das fundações.

A estabilidade (ou solidez) das fundações, segundo Milititsky; Consoli; Schnaid, (2005), pode ser alterada não apenas por problemas relacionados ao carregamento transmitido, mas também, pela possibilidade do solo, no qual a fundação mantém sua estabilidade, apresentar movimentação e instabilidade. Tais movimentações ou deslocamentos da 
massa de solo têm a possibilidade de ocorrência devido a várias atividades da construção civil como explosões, rebaixamento de lençol freático, tráfego intenso, demolições, compactação vibratória de solos.

Em seguida, exemplos comuns de movimentação no solo são de quando ocorrem construções vizinhas a edificações prontas e não é previsto em projeto junta de dilatação entre elas. Outro caso, é a nova construção ser mais pesada do que o empreendimento vizinho gerando, portanto, uma nova carga na fundação podendo ocorrer recalque.

\subsubsection{Execução de grandes escavações próximo às construções}

Uma escavação sempre vai ocasionar a movimentação de solo perto das fundações existentes ou a estruturas de contenção, sendo regulamentada pela norma ABNT NBR 9061/1981 - Execução de escavações a céu aberto. Essa movimentação decorre da perda de material e da mudança no estado inicial de tensão, porém, dependendo do tipo de fundação existente na vizinha e da suscetibilidade da estrutura ao recalque esses efeitos se manifestam de maneiras diferentes.

Dessa forma, essas escavações podem causas diversos danos às edificações vizinhas, instabilidade de elementos de fundação causada pela falta de verificação do efeito de sobrecarga na estabilidade do talude, rompimento de canalizações enterradas, que com provável rompimento podem acarretar em arrastamento de massa de solo, pode ocorrer também, oscilações não previstas no nível de água, rebaixamento do nível de água.

\subsubsection{Vibrações e choques}

Outra forma de causar danos às edificações já existentes é a ocorrência de vibrações e choques internos ou externos provocados por equipamentos industriais, máquinas de compactação de solo e cravação. As fundações mais afetadas com tais ações são as diretas assentes em solos granulares fofos, porém, outros tipos de fundações e solos também podem sofrer efeitos danosos.

As solicitações na massa de solo se alteram com vibrações causadas pela movimentação do solo ao ocorrer cravação por esforços dinâmicos como em estacas pré-moldadas de concreto, por exemplo. Essa alteração pode, portanto, influenciar negativamente estruturas já existentes ou próximas.

Em síntese, as vibrações são mitigadas de forma rápida em solos não-coesivos, porém se propagam a grandes distâncias em solos coesivos.

\subsection{Principais Soluções}

No Brasil, não existe nenhuma ferramenta de registro e acompanhamento das manifestações patológicas nas obras realizadas. Tais avaliações são difíceis de serem executadas em detrimento da falta de relato das ocorrências tanto em obra de pequeno quanto de grande porte. Porém, o aumento dos casos de patologias nas construções e a necessidade de um maior estudo na área é de conhecimento dos profissionais da classe. (MILITITSKY; CONSOLI; SCHNAID, 2005)

\subsubsection{Controles de Recalques}

A realização de controle de recalque é recomendada quando se tem uma escavação de grande porte próxima a estrutura. Este controle pode ser realizado por meio de equipamento topográfico conectado a um marco de referência, dos níveis de carregamento e/ou desenvolvimento dos recalques com o tempo.

Com isso, devem-se levar em consideração alguns cuidados como: a escolha do local de posicionamento do marco de referência; os pontos de medição adequados para facilitar a leitura e o fornecimento de dados para a supervisão do problema.

Os intervalos de tempo em que as medidas são realizadas podem ser diárias, em casos de risco, semanais, em eventos de escavações/execução de tirantes para contenção de seus efeitos, mensais, em casos de rotina, semestrais ou anuais, quando se trata de efeitos a longo prazo. A velocidade de ocorrência é importante tanto quanto as medidas dos recalques realizadas, tendo assim valores usuais vide Tabela 1. (MILITITSKY; CONSOLI; SCHNAID, 2005) 
Tabela 1- Velocidades de ocorrência por dia. Velocidade de ocorrência $\mu /$ dia

\begin{tabular}{cc}
\hline mais de 5 anos & $>10 \mu /$ dia \\
\hline entre 1 e 5 anos & entre 10 e $20 \mu /$ dia \\
\hline fundações superficiais (fase construtiva) & até $200 \mu /$ dia \\
\hline fundações profundas (fase construtiva) & até $80 \mu /$ dia \\
\hline
\end{tabular}

\subsubsection{Controle de Verticalidade}

É indispensável a inspeção de verticalidade em prédios vizinhos quando se tem execução de escavações, fazendose, para tanto, o acompanhamento dos possíveis efeitos produzidos. Esta inspeção é realizada por meio de aparelho topográfico de precisão, efetuando-se leituras periódicas invariavelmente nos mesmos pontos, originando-se em gráficos e planilhas. (MILITITSKY; CONSOLI; SCHNAID, 2005)

A inspeção deve ser realizada de maneira precisa e bem criteriosa, tomando-se sempre cuidado para que os resultados não apresentem valores desconexos. A primeira leitura precisa ser realizada antes do início das atividades, e as demais, após a execução das escavações, para assim ser possível obter valores e efetuar a comparação e análise dos mesmos. Ressalta-se que os valores obtidos na primeira leitura podem não ser necessariamente efeito das escavações, mas sim de problemas durante a construção da própria obra. É mais adequado que essas leituras sejam realizadas pela mesma pessoa e mesmos horários, considerando-se sempre os valores da temperatura, evitando assim, possíveis alterações e superposição de efeitos, dificultando a avaliação. Com tudo, os resultados obtidos necessitam ser encaminhados aos responsáveis, para que possíveis danos ou riscos possam ser identificados de imediato.

\subsubsection{Controle de Trincas}

O acompanhamento de extensão e abertura de trincas se dá como mais um exemplo de supervisão de manifestação patológica. Servem para caracterização do aspecto ativo ou estabilização e intensidade do problema. Essa supervisão pode ser executada com fissurômetros ou paquímetros, e os seus resultados podem ser apontados em forma de estereograma. (MILITITSKY; CONSOLI; SCHNAID, 2005)

Sabe-se que os trincamentos e seus avanços nos elementos portantes são evidências de riscos e necessitam de reparos emergencial, com profissionais adequados. É de extrema importância o acompanhamento da evolução das trincas, fazendo-se registros de sua dimensão, sua descrição e sua classificação.

\subsection{Estudo de Caso}

Partindo do estudo realizado no presente trabalho a respeito das possíveis causas de manifestações patológicas em fundações e do relatório técnico realizado por uma empresa de engenharia contratada pela instituição pública em questão, foi possível analisar questões estruturais e geotécnicas quanto ao tipo de solo e à resistência do concreto. As deformações previstas no Edifício 2 produziram um desalinhamento no eixo vertical entre o módulo A e B e um afastamento nas faces das fachadas entre eles, sendo esses, efeito de um provável recalque nas fundações da edificação.

No projeto inicial das fundações, verifica-se que os tubulões, no local da manifestação patológica, foram executados de acordo como representado na Figura 9:

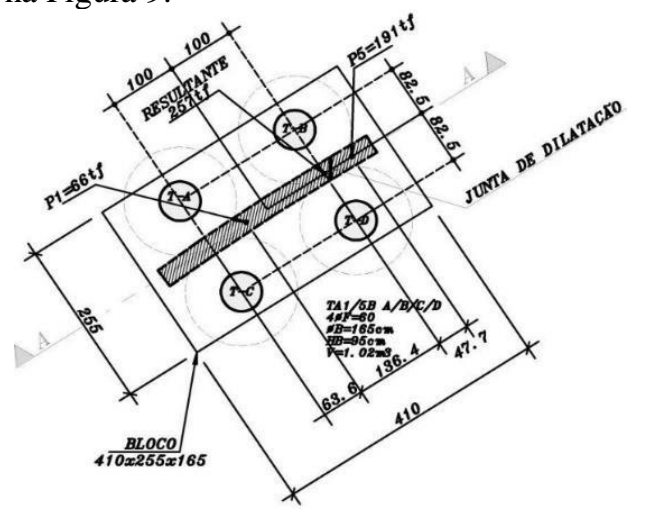

Figura 9 - Planta baixa da locação dos tubulões. 
Isso sugere, portanto, a construção do bloco geometricamente centralizado com os pilares. Porém, verificou-se que as cargas P1 e P5 apresentam uma diferença significante e, com isso, deslocou-se para o eixo entre os tubulões T-B e $\mathrm{T}-\mathrm{D}$, com uma resultante no valor de $\mathrm{R}=257 \mathrm{tf}$. Dessa forma, ao serem realizados os cálculos no software Geotest pela empresa contratada para obter a carga nas fundações seguindo sua geometria e as posições exatas dos pilares, constatouse que apenas o peso próprio do bloco foi dividido pelos quatro tubulões e, portanto, toda a carga da estrutura apenas nos tubulões T-B e T-D.

Tendo isso, essa sobrecarga gerou uma deformação em T-B e T-D, ocasionando um giro no bloco de coroamento, considerando, assim, que os tubulões T-A e T-C não sofreram deformações significativas. Em consequência do pilar parede ligado ao painel de concreto da fachada do bloco A apresentar alta rigidez, o giro do bloco de coroamento tende a separar o pilar 1 (P1) do bloco. Além disso, pelo efeito restaurador e pelo fato de a fachada ser levemente curva, o pilar parede acompanha o giro do bloco de coroamento. Assim, tem-se um efeito de momento torsor do pilar parede para o bloco de coroamento. Na junta de dilatação entre os blocos B e C, entretanto, não sofreram nenhuma movimentação tendo que estas foram projetadas da mesma forma.

Na sequência, foi realizada uma investigação geotécnica onde classificou-se o solo a partir do ensaio SPT como perfil do solo em argila pouco siltosa com areia fina. A fim de constatar que a resistência à compressão do concreto estava de acordo com o projeto realizou-se ensaios destrutivos: retirada de corpo de prova e ensaio de compressão na prensa, e não destrutivos: ensaio de esclerometria no bloco de coroamento das fundações e no pilar parede, P1A, que se apoia no bloco. Dessa forma, encontrou-se uma resistência de $40 \mathrm{MPa}$, conforme especificado no projeto inicial da fundação.

Ao se realizar a investigação em volta do bloco de coroamento, por meio de escavação, encontrou-se uma rede de esgoto próxima ao fundo do bloco, e uma caverna indo em direção à parte interna do prédio, onde se localizam as caixas de esgoto, gordura e sabão, e também a grelha de águas pluviais (Figura 10).

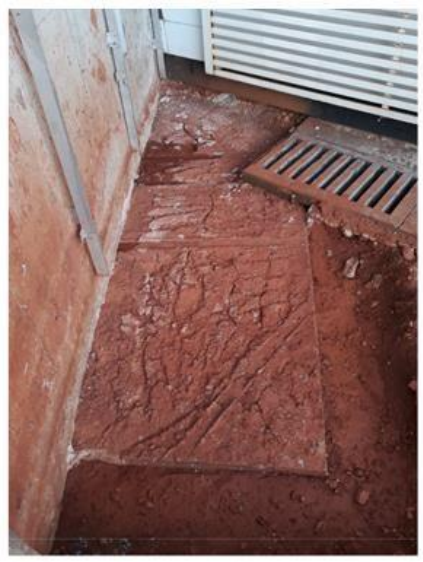

Figura 10 - Localização das caixas de inspeção.

Identificou-se na área interna do módulo A uma pequena região com depressão por perda de solo, podendo ser ocasionada por um plausível vazamento de águas pluviais ou esgoto. Com isso, ocorre um vínculo entre a área interna e o bloco de coroamento, transferindo água de um lado para o outro por motivo da não compactação adequada do solo em volta do bloco.

Por último, foi informado por funcionários da empresa em estudo que no final do ano de 2017 foi realizada a demolição e a remoção do galpão que ficava nas proximidades do local da manifestação patológica.

Desta forma, perante todos os acontecimentos expostos no presente trabalho, a solução proposta pela contratada é primeiramente o remanejamento das caixas de inspeção de esgoto encontradas ao lado do fundo do bloco de coroamento por estarem localizadas onde serão executadas as estruturas do reforço. A execução do reforço do bloco de coroamento das fundações, bem como, executar o retorno da parede curva para sua posição original visto que a mesma sofreu uma rotação, e também recuperar o pilar parede P1A.

Assim sendo, em consonância com o relatório técnico aqui especificado, sem avaliação de viabilidade econômica e ambiental, adotando apenas o critério técnico, este estudo apresenta concordância das causas e soluções propostas pela empresa de Engenharia contratada. 


\section{CONCLUSÃO}

No decorrer do estudo de caso realizado na presente pesquisa, pode-se constatar a importância e, concomitantemente, a carência de estudos de manifestações patológicas em obras civis, bem como a importância das manutenções preditivas, preventivas e corretivas, com a finalidade de evitar a ocorrência dos casos de patologias apresentados. Sendo esses de grande relevância à uma construção, não se pode deixar passar, podendo assim antecipar a sua atividade fim, precisando de ajustes/recuperação, reforço das estruturas, ou, até mesmo, a necessidade de demolição.

Com o objetivo de realizar um estudo de caso em relação ao edifício em questão, foi mapeada os principais problemas de manifestações patológicas em fundações, assim como, as principais causas, erros na execução e possíveis soluções.

No estudo de caso do Banco público localizado em Brasília, onde já havia sido realizado inspeções, ensaios geotécnicos e um relatório técnico, foi necessário executar o reforço do bloco de coroamento das fundações, o retorno da parede curva para sua posição original, recuperação do pilar parede, e desvio das caixas de inspeção e esgoto.

Desta forma, fica evidente, que há a necessidade de ampliar as pesquisas realizadas na área sobre as manifestações patológicas: como visto no estudo de caso, a execução do retorno da parede curva para o seu local inicial, sem prejudicar o restante da estrutura; como também proposto, meios para redução de impactos das vibrações próximas a estruturas já existentes e, finalmente, o estudo de análise de dados das torções identificadas na parede.

\section{REFERÊNCIAS}

ASSOCIAÇÃO BRASILEIRA DE NORMAS E TÉCNICAS. NBR 5462: Confiabilidade e mantenabilidade. Rio de Janeiro, 1994.

ASSOCIAÇÃO BRASILEIRA DE NORMAS E TÉCNICAS. NBR 6122: projeto e execução de fundações. Rio de Janeiro, 2010.

ASSOCIAÇÃO BRASILEIRA DE NORMAS E TÉCNICAS. NBR 8038: Programação de sondagens de simples reconhecimento dos solos para fundações de edifícios - Procedimento. Rio de Janeiro, 1983.

ASSOCIAÇÃO BRASILEIRA DE NORMAS E TÉCNICAS. NBR 9061: Segurança de escavação a céu aberto Procedimento. Rio de Janeiro, 1981.

GOOGLE. Google Earth. Banco Público. Disponível em: https://earth.google.com/web/@ 15.73738017,47.90338369,1045.82934085a,1012.2393761d,35y,144.10518601h,44.99999918t,-

0r/data=ChUaEwoLL2cvMXRrc2p3bDIYASABKAI. Acesso em: 02 out. 2019.

INTERNATIONAL ORGANIZATION FOR STANDARDIZATION. ISO 13823: general principles on the design for structures for durability. Suíça, 2008.

MILITITSKY, Jarbas; CONSOLI, Nilo Cesar; SCHNAID, Fernando. Patologia das fundações. São Paulo: Oficina de Textos, 2005.

MÍSULA ENGENHARIA. Relatório de estudo sobre patologias apresentadas no Edifício de Banco Público no DF. Brasília, 2018.

VITÓRIO, Afonso. Fundamentos da patologia das estruturas nas perícias de engenharia. Recife: IPEAPE, 2003. 